\title{
Molecular Characteristics of the Equine Periodontal Ligament
}

\author{
Antje Pöschke ${ }^{1}$, Bastian Krähling ${ }^{1}$, Klaus Failing ${ }^{2}$ and Carsten Staszyk ${ }^{1 *}$ \\ 'Institute of Veterinary-Anatomy, -Histology and -Embryology, Justus Liebig University Giessen, Giessen, Germany, \\ ${ }^{2}$ Department of Biomathematics, Justus Liebig University Giessen, Giessen, Germany
}

\section{OPEN ACCESS}

Edited by:

Padraic Martin Dixon,

University of Edinburgh,

United Kingdom

Reviewed by:

Peter Clegg,

University of Liverpool,

United Kingdom

Mathew Gerard,

North Carolina State University,

United States

*Correspondence:

Carsten Staszyk

carsten.staszyk@vetmed.

uni-giessen.de

Specialty section:

This article was submitted to

Veterinary Dentistry and

Oromaxillofacial Surgery,

a section of the journal

Frontiers in Veterinary Science

Received: 17 January 2017

Accepted: 14 December 2017

Published: 11 January 2018

Citation:

Pöschke A, Krähling B, Failing K and Staszyk C (2018) Molecular

Characteristics of the Equine

Periodontal Ligament.

Front. Vet. Sci. 4:235.

doi: 10.3389/fvets.2017.00235
The equine periodontal ligament (PDL) is a fibrous connective tissue that covers the intra-alveolar parts of the tooth and anchors it to the alveolar bone-it, therefore, provides a similar function to a tendinous structure. While several studies have considered the formation and structure of tendons, there is insufficient information particularly on the molecular composition of the PDL. Especially for the equine PDL, there is limited knowledge concerning the expression of genes commonly regarded as typical for tendon tissue. In this study, the gene expression of, e.g., collagen type 1 alpha 1 (COL1), collagen type 3 alpha 1 (COL3), scleraxis (SCX), and fibrocartilage markers was examined in the functional mature equine PDL compared with immature and mature equine tendon tissue. PDL samples were obtained from incisor, premolar, and molar teeth from seven adult horses. Additionally, tendon samples were collected from four adult horses and five foals at different sampling locations. Analyses of gene expression were performed using real-time quantitative polymerase chain reaction (qRT-PCR). Significantly higher expression levels of COL 1 and 3 were found in the mature equine $\mathrm{PDL}$ in comparison with mature tendon, indicating higher rates of collagen production and turnover in the mature equine PDL. The expression levels of SCX, a specific marker for tenogenic-differentiated cells, were on a similar level in functional mature PDL and in mature tendon tissue. Evidence of chondrogenic metaplasia, often found in tendon entheses or in pressurized regions of tendons, was not found in the mature equine PDL. The obtained results justify further experiments focused on the possible use of equine PDL cells for cell-based regenerative therapies.

Keywords: periodontal ligament, tendon, collagen, scleraxis, equine

\section{INTRODUCTION}

The equine periodontal ligament (PDL) is part of a complex formation called the periodontium. The basic periodontium structure consists of four components termed the PDL, the alveolar bone, the dental cementum, and the gingiva $(1,2)$. Its central function is to fix the tooth in the alveolus. Moreover, it has the task of absorbing and discharging masticatory tension and compression forces (3-6). The PDL of brachydont (short-crowned) as well of that of hypsodont (high-crowned) species comprises collagen fibers surrounded by ground substance containing various types of cells, blood vessels, and nerves $(7,8)$. Equine hypsodont teeth are an adaption to the very abrasive silicate-rich food of herbivores (6). One major challenge for the equine PDL is to accomplish continuous eruption throughout the life of the animal, in response to a permanent occlusal wear of 3-4 mm per year $(1,9$, 10). Thus, in horses, the components of the periodontium must enable tooth support while managing continuous tooth eruption. Consequently, a very dynamic system is needed, which is capable of both 
continuous collagen remodeling and permanent provision of a sufficient apparatus to withstand biomechanical loads similar to those in a load-bearing tendon.

Several studies in different species have addressed the collagen fiber apparatus and extracellular matrix (ECM) composition of tendons (11-14) and their entheses $(15,16)$. The distinctive formation of a tendinous structure is composed of numerous fiber bundles arranged along the long axis of the tendon embedded in a well-coordinated ECM $(12,17)$. COL1 is the primary protein in tendinous structures, accompanied to a much lesser extent by $\operatorname{COL} 3(13,17,18)$. The transcription factor scleraxis (SCX) plays a key role during tenogenic and ligamentogenic differentiation (19-23). As SCX is also expressed in mature tendinous tissue, it is generally accepted as a specific marker to identify differentiated tenogenic and ligamentogenic cells $(22,24)$.

Tendon and PDL tissues are subjected to tensile and shear forces, as well as compression loads in distinct regions, e.g., near entheses or where they wrap around bony or fibrous pulleys $(15,16,25)$. Entheses are specialized fibrocartilaginous or fibrous regions where tendons and ligaments are attached to bone $(15,16)$. Local compression loads can trigger tendon tissue to produce cartilage-like matrix, which subsequently transforms into fibrocartilage tissue $(15,26)$. A predominant fibrocartilaginous area in the superficial digital flexor tendon is the place where it is overlying the metacarpophalangeal joint $(15,25,27)$. In these regions, characteristic protein expression of type II collagen (COL2), cartilage oligomeric matrix protein (COMP), and aggrecan (ACAN) is present. Osteopontin (OPN), a protein related to osteogenesis, can also be found in the region of entheses (28).

During tendon maturation, cells that are capable of tenogenesis drift more and more into the background and shift into a status of limited metabolic activity (bradytrophy) $(14,29,30)$. It is supposed that mature tendon tissue is a primarily static tissue with a low turnover and limited regenerative and reparative capacities (14, 18, 19, 31-34). Therefore, healing processes (for example after tendon injuries) represent a common orthopedic problem (19). The PDL has completely different characteristics-cellular components exist in large numbers with up to $50 \%$ of total volume $(7,35,36)$, while extracellular components are subjected to constant synthesis and degradation, which is described as continuous remodeling $(37,38)$. In brachydont rodent molars, proliferation rates of about $2 \%$ have been observed $(36,37,39$, 40). Studies in the PDL of brachydont species, including humans, have revealed that cell turnover is balanced between proliferation and apoptosis (36). To maintain tissue homeostasis under physiological conditions, synthesis and degradation of periodontal structures must be harmonized $(41,42)$. Nevertheless, external forces, e.g., as a result of orthodontic tooth movement, increase the amount of periodontal remodeling in order to adapt the periodontal environment to the shifting teeth. It is supposed that the PDL of hypsodont equine teeth resembles the PDL of brachydont teeth under conditions of orthodontic tooth movement (38). It can, therefore, be assumed that in the equine PDL, processes run continuously, which only temporarily occur in tendons during tenogenesis or repair.

Thus, the aim of the present study was to compare the mature equine PDL with immature and mature equine tendon tissue with regard to the expression patterns of genes involved in tenogenesis. Based on these criteria, the question arises as to whether PDLderived cells exhibit characteristics that can be generally useful in cell-based therapies for tendon diseases.

\section{MATERIALS AND METHODS}

\section{Animals and Sample Collection}

Specimens of different tissues were taken from five foals and seven adult horses, which had died or were euthanized on humane grounds unrelated to this study at the Clinic of Maternity, Gynecology, and Andrology and at the Clinic for Horses-Internal Medicine, Faculty of Veterinary Medicine, Justus Liebig University Giessen, Germany. The animals were of different genders and ages (the age range of the foals was about 4 weeks pre-parturition to 2 days post-parturition, and the age range of the adult horses was from 7 to 27 years). Samples were taken immediately post euthanasia or post mortem within a time frame of $2 \mathrm{~h}$. PDL samples were taken from incisor, premolar, and molar teeth of the left mandible $(301,306,309)$ from seven adult horses. For sample collection, a $4.5 \mathrm{~cm} \times 4.5 \mathrm{~cm}$ square plate was sawn out of the alveolar bone to get access to the PDL (oscillating saw HB 8891, HEBUmedial GmbH, Tutlingen, Germany). PDL tissue was collected by gently scraping of the tooth surface with scalpel and tweezer, avoiding to sample parts of the alveolar bone. PDL samples were obtained from the labial and the buccal side, respectively. Tendon samples [i.e., superficial and deep digital flexor tendon, common digital extensor tendon and accessory (check) ligament of the deep digital flexor tendon of the left forelimb and tendon of the sternomandibularis muscle] were taken from four of the seven adult horses (aged 18-27 years) and five foals (aged 4 weeks pre-parturition to 2 days post-parturition). Each tendon sample, e.g., superficial and deep digital flexor tendon as well as the common digital extensor tendon were sampled in the mid-metacarpus region, the accessory (check) ligament of the deep digital flexor tendon was sampled in the middle of its proximodistal extension and the tendon of the sternomandibularis muscle was sampled in the middle of its craniocaudal extension. Samples were taken from the tendon core.

\section{RNA Extraction}

Periodontal ligament and tendon samples were transferred to $1.7 \mathrm{ml}$ reaction tubes containing $1 \mathrm{ml}$ peqGOLD ${ }^{\circledR}$ TriFast $^{\mathrm{TM}}$ (Peqlab, Biotechnology GmbH, Erlangen, Germany). Prior to RNA extraction, specimens were homogenized with an Ultra Turrax $^{\circledR}$ homogenizer. Total RNA was isolated from the cells according to the manufacturer's protocol. The RNA concentration was measured using an absorption photometer (BioPhotometer, Eppendorf AG, Hamburg, Germany). To guarantee the purity of the RNA, the ratio of sample absorbance at 260 and $280 \mathrm{~nm}$ was calculated. RNA samples were immediately frozen in liquid nitrogen and then stored at $-196^{\circ} \mathrm{C}$.

\section{DNAse Treatment and Transcription}

Isolated total RNA was used at a concentration of $200 \mathrm{ng} / \mu \mathrm{l}$. Subsequently, genomic DNA was digested using DNAse I 
(Roche, Grenzach, Germany). Reverse transcription was performed using a reaction mix containing $50 \mathrm{U}$ Reverse Transcriptase, RNAse Inhibitor $(20 \mathrm{U} / \mu \mathrm{l})$, Random Hexamers, dNTP mix, $\mathrm{MgCl}_{2}$, and PCR Buffer Gold (all products of Invitrogen-Life Technologies, Darmstadt, Germany). Negative control samples were employed, omitting reverse transcriptase from the reaction mixtures (minus-RT). Successful cDNA synthesis and absence of genomic DNA in minus-RT controls was tested using a qualitative PCR for glyceraldehyde-3-phoshpate dehydrogenase (GAPDH, forward: $5^{\prime}$-gcg tga acc acg aga at atg a-3' and reverse $5^{\prime}$-ggt ggt gca gga ggc att g-3', Eurofins Genomics, Eberberg, Germany).

\section{Real-time Quantitative Polymerase Chain Reaction (qRT-PCR)}

According to the manufacturer's protocol, the qRT-PCR was performed with $1 \mu \mathrm{l}$ cDNA and $12.5 \mu \mathrm{RT}^{2}$ SYBR Green Mastermix (Qiagen, Hilden, Germany) combined with $1 \mu \mathrm{l} \mathrm{RT}^{2}$ qPCR Primer Assay (Qiagen, Hilden, Germany) and $10.5 \mu \mathrm{l}$ water, using a BioRad CFX96 Touch Real-time PCR Detection System (BioRad Laboratories, Munich, Germany). An initial denaturation at $95.0^{\circ} \mathrm{C}$ for $10: 00 \mathrm{~min}$ was followed by 40 cycles with two steps: $95.0^{\circ} \mathrm{C}$ for $0: 15 \mathrm{~min}$ and $55.0^{\circ} \mathrm{C}$ for $0: 30 \mathrm{~min}$. The run was finished with a single step of $72.0^{\circ} \mathrm{C}$ for $0: 30 \mathrm{~min}$ before a melt curve from $60.0^{\circ} \mathrm{C}$ to $95.0^{\circ} \mathrm{C}$ (increment $0.5^{\circ} \mathrm{C}$ ), to ensure specificity, was carried out.

The following equine $\mathrm{RT}^{2} \mathrm{qPCR}$ primer assays were used for analysis: $A C A N$ (Qiagen-ID: PPE00103A), COL1A1 (Qiagen-ID: PPE00104A), COL2A1 (Qiagen-ID: PPE00009A), COL3A1 (Qiagen-ID: PPE00310A), COMP(Qiagen-ID: PPE00133A), OPN (Qiagen-ID: PPE08493A), and SCX (Qiagen-ID: PPE06980A). As reference genes, GAPDH (Qiagen-ID: PPE00120A) and $\beta$-Actin (Qiagen-ID: PPE00105A) were selected.

For all genes, the same cDNA per probe was used to investigate the expression and all genes were tested in triplicate for each probe to avoid pipetting mistakes. A no-template-control was included for each gene to exclude contamination. Data were analyzed using the BioRad CFX Manager ${ }^{\mathrm{TM}}$ Software (version 3.0) applying the $\Delta \Delta \mathrm{Ct}$-method for gene expression, relative to the two reference genes GAPDH and $\beta$-Actin. For inter-run calibration, cDNA from equine mesenchymal stroma cells was pooled and used as a PCR template in every run.

\section{Statistical Analysis}

Statistical analyses were performed using the statistical program package BMDP (43). To identify differences in gene expression between the three differently located PDL samples $(301,306,309)$ and, among the other, the five tendon sample locations in adult horses, we used one-way analysis of variance (ANOVA) with repeated measurements (program BMDP5V). Subsequently, the mean gene expression values in PDL and tendon samples from all locations were calculated for each horse. To detect differences in gene expression between mature PDL and mature tendon samples, a $t$-test for dependent samples was employed (program BMDP3D). A two-way ANOVA with repeated measurements with respect to location (program BMDP5V) was used to test for gene expression differences between mature and immature tendon samples, also taking differences between the locations into account. Differences between mature PDL and immature tendon were assessed descriptively (without statistical analysis) because of not comparable conditions (different tissues and ages). The outcome of the statistical tests was considered to be significant when $p \leq 0.05$. Boxplot generation was performed using GraphPad Prism 6 (GraphPad Software, La Jolla, CA, USA).

\section{RESULTS}

\section{One-Way ANOVA with Repeated Measures}

Significant differences were detected among the three differently located PDL samples from mature horses only for COL2 gene expression (301, 306, 309). Among the five different tendon samples in mature horses, a significant difference was observed only for $A C A N$ gene expression. Statistical analysis of $O P N$ gene expression was not possible for adult tendons because of missing measurement values. Although there were significant differences within PDL and tendon samples, the mean gene expression values for all PDL and all tendon samples for each horse were calculated and the $t$-test for dependent samples was used to detect differences in gene expression between mature PDL and mature tendon (Figure 1).

\section{Two-Factorial ANOVA with Repeated Measurements}

Except for COL3, no statistical differences were detected between mature and immature tendon samples taking differences between the locations into account. In terms of the global group differences, no statistical differences between mature and immature tendon could be detected. Analysis of OPN gene expression was not possible because of missing measurement values.

\section{Relative Gene Expression of COL1}

The highest relative gene expression values for COL1 were noted in immature tendon (Table 1; Figure 1A). The COL1 expression in mature PDL was significantly higher than in mature tendon tissue $(p<0.05$, Figure 1A).

\section{Relative Gene Expression of COL3}

The relative COL3 expression in mature PDL was significantly higher than in mature tendon $(p<0.05$, Figure 1B). Analysis of COL 3 expression levels revealed no statistical difference between mature tendon and immature tendon tissue (for global group differences).

\section{Ratio between Mean Relative COL1 and COL3 Gene Expressions}

In the mature equine PDL, the ratio between the relative gene expression values for COL1 and COL3 was 3.3:1 (76.5-23.5\%, Figure $1 \mathrm{C}$ ). In the mature tendon, a COL1 to COL3 ratio of 0.9:1 (53.8-46.2\%) was found, while in immature tendon the ratio was 34:1 (97.2-2.8\%, Figure 1C). 

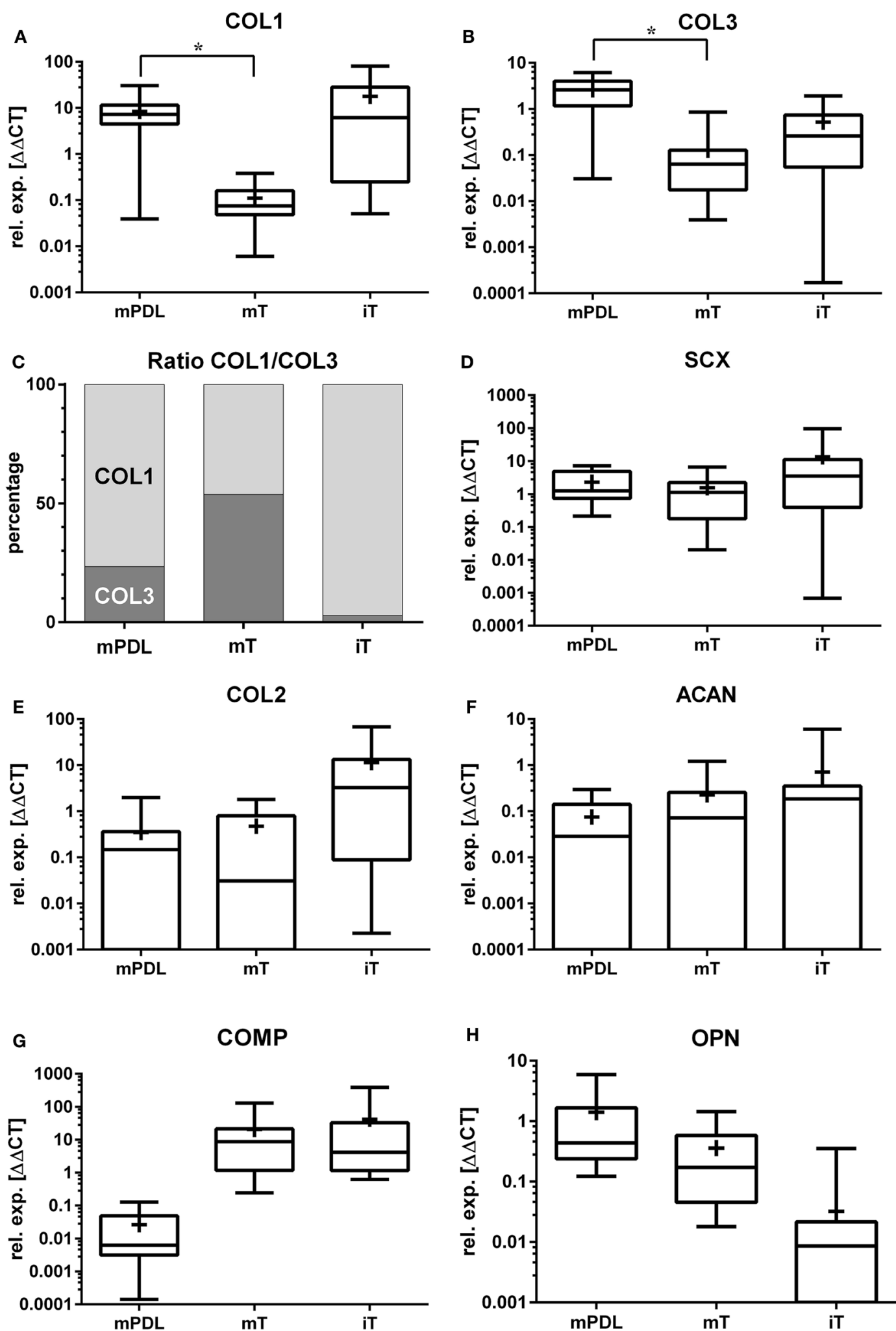

FIGURE 1 | Relative gene expression (rel. exp. [ $\Delta \Delta \mathrm{Ct}$ ]) is presented as logarithmic application (log10) of the analyzed genes (A) collagen type 1 alpha 1 (COL1), (B) collagen type 3 alpha 1 (COL3), (C) ratio of mean relative expressions of COL1/COL3, (D) scleraxis (SCX), (E) collagen type 2 alpha 1 (COL2), (F) aggrecan $(A C A N),(\mathbf{G})$ cartilage oligomeric matrix protein (COMP), and $\mathbf{( H )}$ osteopontin (OPN) in mature PDL (mPDL), mature tendon (mT), and immature tendon (iT). Mean relative gene expression is shown as plus $(+)$. Statistical significance is shown as ${ }^{*} p$-value $\leq 0.05$. 
TABLE 1 | Mean, minimum, and maximum relative gene expression ( $\Delta \Delta \mathrm{Ct})$ of the analyzed genes [collagen type 1 alpha 1 (COL1), collagen type 3 alpha 1 (COL3), scleraxis (SCX), aggrecan (ACAN), cartilage oligomeric matrix protein $(C O M P)$, and osteopontin (OPN)] in mature PDL (mPDL), mature tendon $(\mathrm{mT})$, and immature tendon (iT).

\begin{tabular}{llccc}
\hline & & mPDL & mT & iT \\
\hline COL1 & Min-max & $0.039-30.64$ & $0.0061-0.38$ & $0.051-80.57$ \\
& Mean & 8.46 & 0.11 & 17.79 \\
\hline COL3 & Min-max & $0.031-6.19$ & $0.0039-0.86$ & $0.00017-1.91$ \\
& Mean & 2.59 & 0.13 & 0.52 \\
\hline SCX & Min-max & $0.21-7.19$ & $0.02-6.59$ & $0.00069-96.4$ \\
& Mean & 2.29 & 1.55 & 13.5 \\
\hline COL2 & Min-max & $0-1.98$ & $0-1.8$ & $0.0023-67.5$ \\
& Mean & 0.35 & 0.47 & 11.38 \\
\hline \multirow{2}{*}{ ACAN } & Min-max & $0-0.3$ & $0-1.22$ & $0-6.02$ \\
& Mean & 0.075 & 0.23 & 0.71 \\
\hline COMP & Min-max & $0.00014-0.13$ & $0.25-128.8$ & $0.62-388$ \\
& Mean & 0.026 & 20.51 & 41.81 \\
\hline OPN & Min-max & $0.12-5.91$ & $0.018-1.45$ & $0-0.35$ \\
& Mean & 1.41 & 0.36 & 0.032 \\
\hline
\end{tabular}

\section{Relative Gene Expression of SCX}

Gene expression of SCX exhibited no significant differences between mature PDL and mature tendon or between immature and mature tendon (Figure 1D). The expression values of SCX in immature tendon tissue were highly variable (Figure 1D; Table 1).

\section{Relative Gene Expression of COL2}

The highest relative expression values for COL2 were observed in immature tendon tissue (Figure 1E; Table 1). No statistical differences between gene expression in mature PDL and mature tendon or between immature and mature tendon were observed (Figure 1E).

\section{Relative Gene Expression of ACAN}

The highest relative expression values, which were also highly variable, were noted in immature tendon tissue (Table 1). No statistical differences between $A C A N$ gene expression in mature PDL and mature tendon or between immature and mature tendon were detected (Figure 1F).

\section{Relative Gene Expression of COMP}

The highest relative expression values for COMP, which were also highly variable, were observed in immature tendon tissue (Table 1). No statistical differences between COMP gene expression in mature PDL and mature tendon or between immature and mature tendon were observed (Figure 1G).

\section{Relative Gene Expression of OPN}

The highest relative gene expression values for $O P N$ were seen in mature PDL (Table 1; Figure 1H). No statistical differences between $O P N$ gene expression in mature PDL and mature tendon or between immature and mature tendon were detected (Figure 1H).

\section{DISCUSSION}

Currently, stem cell-based therapies for equine tendon regeneration are receiving increasing attention in the field of equine orthopedics $(44,45)$. Stem cells can be derived from different sources, i.e., bone marrow, adipose tissue, peripheral blood, etc. (46-51). Although promising results using those cells have been reported (52), it is still unclear how, and to what extent those cells contribute to tendon regeneration. In order to improve the efficiency of such cells, it has been suggested that stem cells could be induced to differentiate into the tenogenic lineage in vitro, prior to possible therapeutic use $(47,53)$. However, in vitro tenogenic predifferentiation requires a high degree of technical effort. There are only a few reports of the practical use of such cells for regenerative therapies in horses $(54,55)$. Therefore, we aimed to find a source of cells that possess a wide range of regenerative properties and, at the same time, feature characteristics of tenogenic tissue. These prerequisites are broadly met by equine periodontal tissue cells. A promising study in a rat model gave the first positive indications for the use of PDL cells in tendon injuries (56). To confirm the suspected characteristics of such cells, functional mature equine PDL was compared to mature and immature tendon tissue at the molecular level.

In the equine PDL, continuous remodeling is required to accomplish permanent regeneration of the participating structures (37). For this reason, the PDL has a more cellular character than tendon tissue, and a high percentage of PDL cells are fibroblasts and fibrocytes (7). In the PDL of hypsodont mouse incisors, $50 \%$ of the volume is represented by fibroblast-like cells, while brachydont mouse molars showed a $10-15 \%$ smaller volume $(35,57)$. As a key factor for maintaining remodeling abilities in the PDL, a high population of fibroblasts is required (58). In brachydont molars of rats and mice, fibroblast proliferation rates of about $2 \%$ have been observed $(39,40)$. In the equine PDL, similar proliferation rates have been observed, indicating a relatively rapid turnover in comparison to tendon tissue, for example (37). Interestingly, in some regions of the equine PDL, proliferation rates of up to $4.5 \%$ have been measured (37). In contrast, tendon tissue has been described as a primarily static tissue $(59,60)$ with restricted regeneration capacity $(14,18,19,31-33,59)$. About 90-95\% of the tendon core collagen is not involved in turnover, and is in a stable state at adolescence, whereas only $5-10 \%$ of the collagen shows a higher rate of turnover (34). During maturation, cell proliferation is diminished and the number of stem cell progenitors decreases (59). Our observations in mature equine tendon showed that the expression of COL1 and 3 is at a very basal level in this tissue. This result is consistent with the previously described characteristics of mature tendon tissue, indicating very limited collagen turnover. The relative gene expressions of COL1 and COL3 in mature tendon were similar (ratio 1.1:1), although, considering that COL1 is the main protein comprising the mature tendon, a considerably higher expression of COL1 could be expected. This observation might be explained by the fact that collagen is accumulated in the developing tendon until a mature, more static state is reached $(30,61)$, and furthermore, limited turnover rates of collagens are detectable $(34,59)$. In the mature tendon, COL3 represents only a small amount of the ECM 
protein, whereas during tenogenesis, a considerably higher initial level of COL3 expression has been documented (62). During development, the COL3 expression decreases, while at the same time, the fibril diameters are increasing (62). These observations underline the function of COL3 as a crucial regulator during COL1 fibrillogenesis (62-64). Moreover, COL3 plays a key role during tendon healing and repair.

In contrast to the mature tendon, significantly higher expression levels of COL1 and 3 characterize the mature equine PDL, indicating higher rates of collagen production and turnover. This finding is in line with previous studies that have documented a distinct spatial and temporal pattern of collagen remodeling in the equine PDL $(37,38)$. The relationship between expression of COL 1 and COL 3 in the mature PDL should be highlighted [ratio 3.3:1 (77-23\%)]. The COL3 gene expression in the mature equine PDL is consistent with the COL3 protein content determined in the mature PDL of other hypsodont (65) and brachydont species (66). Similar COL3 expression has also been reported for fetal tissues (66-68). In this respect, the mature equine PDL seems to have embryonic-like properties and features high turnover rates.

In the immature tendon, the situation is quite different, with a striking expression of $C O L 1$ and a comparatively lower expression of COL3 (ratio 34:1). This result may reflect the fact that postnatal tendon growth predominantly occurs through an increase in collagen fiber diameter and length until the mature and more static state is reached $(30,61)$.

Another remarkable observation in our study was the fact that no statistical differences could be detected between the gene expression values for SCX in mature PDL and mature tendon tissue. $S C X$ is a transcription factor that represents a precise marker of tendon and ligament progenitors as well as differentiated cells (22-24). SCX is, therefore, expressed in mature tendon tissue in which the inhibited tenocytes feature a highly bradytrophic metabolism, without any significant production of collagens in most areas $(29,30)$. Murchison and colleagues have described remarkable deficits in matrix and collagen fiber organization and a decreased number of tenocytes in $\mathrm{SCX}^{-1-}$ (knockout) mice flexor digitorum profundus tendons, which indicates the regulatory function of SCX in normal tendon development. A positive regulation of COL1 synthesis by SCX in tenocyte cells could also be demonstrated (24). Studies in mice molar PDL cells revealed similar gene expression levels for SCX in PDL cells compared to tenocytes (69). This observation is in agreement with our results. SCX was shown to regulate pro- $\alpha 1$ (I) collagen in tenocytes and to regulate COL1A1 transcription through binding to tendon specific element 2 (70). Maeda and colleagues demonstrated that a progressive loss in tensile load results in reduced $S C X$ expression with a significant reduction in tendon COL1 fibrils (71). Moreover, the abovementioned study in rodent molar PDL cells revealed that orthodontic tooth movement, in other words, tensile forces on PDL cells, results in SCX expression (69). Takimoto and colleagues described an inhibitory effect of SCX overexpression on ECM mineralization and hypothesized possible functions of SCX as a regulator of PDL width and in prevention of ankyloses (69). Additionally, it was shown that SCX negatively regulates the expression of OPN, a mineral-associated protein, after osteogenic stimuli (69). OPN is a prominent marker for osteogenic differentiation. Our results lead to the suggestion that the initial definition of SCX as a marker for connective tissues that attach muscle to bone (22) might be extended to the PDL, as a tendon-like structure, which connects tooth to bone.

Osteogenesis-related genes can be detected at the tendonbone insertion, and their expression is thus found in the calcified fibrocartilage zone of the entheses from mice (28). In our study, a remarkably high level of OPN expression was detected in the mature equine PDL. This observation might be a result of the sampling technique, if there was unintentional removal of osteoblasts from the side of the alveolar bone. Another possible explanation could be the suggestion made by Mori and colleagues that OPN functions in the regulation of tissue remodeling (72).

Local compression loads can induce tendon tissue to produce cartilage-like matrix (26) and subsequently transform it into fibrous cartilage tissue, e.g., in tendons that wrap around bony or fibrous pulleys (15). More precisely, pressurized regions within tendons can undergo a local transformation from tight collagenous tendon tissue into fibrocartilage. This conversion can also be described as chondrogenic metaplasia. Therefore, we examined the expression of characteristic fibrocartilage genes like COL2, $C O M P$, and $A C A N$. Fibrocartilage can be found within fascicles, and in the endo- or epitenon, where it helps to prevent blood vessels from compression stresses or contributes to improved sliding between fascicles (15). Furthermore, it is supposed that tendon tissue is generally able to synthesize a cartilage-like matrix along the tendon to adapt to changing mechanical conditions (26). Considering the position of the equine PDL (between the teeth and the alveolar bone) and its biomechanical environment, in which remarkable tensile and compressive stresses occur $(10,73$, 74), chondrogenic metaplasia should be expected. However, it has not been documented in the literature nor was gene expression related to chondrogenic metaplasia detected in this study. There has been speculation that the PDL possesses distinct mechanisms that prevent functionally disadvantageous chondrogenic metaplasia. A possible explanation is provided by the current opinion that epithelial cell rests of Malassez perform an important function in maintaining PDL tissue homeostasis (75). It is believed that epithelial cell rests of Malassez counteract ankylosis by maintaining the PDL space (75). The ECM in fibrocartilaginous regions often comprises ACAN and COL2. These components enable tendons to absorb water and resist compression stresses (15). COL2 distribution varies between different tendons and subjects, presumably dependent on differing load and compression forces (15). In the present study, although no differences in $A C A N$ or COL2 gene expression were detected between the equine PDL, and the mature and immature tendon, the high variability in the expression levels between immature specimens are noteworthy. However, a functional explanation remains open.

In summary, scientific interest in understanding molecular-, growth-, and turnover mechanisms in tendons remains high, with the aim of obtaining important information about healing processes and new therapies. Tendon injuries represent a far-ranging problem in equine orthopedics. The observed low collagen expression rates in mature tendon tissue indicate limited turnover. This circumstance, together with the minor cellularity 
and vascularity, leads to poor regeneration capacity in tendon tissue. In contrast, the mature equine PDL can be described as a highly dynamic system, with high collagen expression contributing to continuous remodeling. On the molecular level, the equine PDL exhibits a tendon related gene expression profile. Based on our preliminary results, additional studies are required to further characterize equine PDL-derived MSC and to evaluate their possible use in cell-based regenerative therapies.

\section{ETHICS STATEMENT}

According to German legislation, the postmortem harvest of specimens does not need any permission of the animal welfare authority. The former owners of the horses consent to post mortem dissection.

\section{REFERENCES}

1. Staszyk C, Bienert-Zeit A. The equine periodontium: the (re)model tissue. Vet J (2012) 194:280-1. doi:10.1016/j.tvjl.2012.08.015

2. Cho MI, Garant PR. Development and general structure of the periodontium. Periodontol 2000 (2000) 24:9-27. doi:10.1034/j.1600-0757.2000.2240102.x

3. Lee Y, Nahm D, Jung Y, Choi J, Kim SG, Cho M, et al. Differential gene expression of periodontal ligament cells after loading of static compressive force. J Periodontol (2007) 78:446-52. doi:10.1902/jop.2007.060240

4. McCormack SW, Witzel U, Watson PJ, Fagan MJ, Gröning F, Agarwal S. The biomechanical function of periodontal ligament fibres in orthodontic tooth movement. PLoS One (2014) 9:e102387. doi:10.1371/journal.pone.0102387

5. Feller L, Khammissa RAG, Schechter I, Thomadakis G, Fourie J, Lemmer J. Biological events in periodontal ligament and alveolar bone associated with application of orthodontic forces. Sci World J (2015) 2015:1-7. doi:10.1155/2015/876509

6. Staszyk C, Gasse H. Distinct fibro-vascular arrangements in the periodontal ligament of the horse. Arch Oral Biol (2005) 50:439-47. doi:10.1016/j. archoralbio.2004.10.001

7. Berkovitz BK. The structure of the periodontal ligament: an update. Eur J Orthod (1990) 12:51-76. doi:10.1093/ejo/12.1.51

8. Beertsen W, McCulloch CA, Sodek J. The periodontal ligament: a unique, multifunctional connective tissue. Periodontol 2000 (1997) 13:20-40. doi:10.1111/j.1600-0757.1997.tb00094.x

9. Dixon PM, Dacre I. A review of equine dental disorders. Vet J (2005) 169:165-87. doi:10.1016/j.tvjl.2004.03.022

10. Schrock P, Lüpke M, Seifert H, Staszyk C. Finite element analysis of equine incisor teeth. Part 2: investigation of stresses and strain energy densities in the periodontal ligament and surrounding bone during tooth movement. Vet J (2013) 198:590-8. doi:10.1016/j.tvil.2013.10.010

11. Thorpe CT, Birch HL, Clegg PD, Screen HR. The role of the non-collagenous matrix in tendon function. Int J Exp Pathol (2013) 94:248-59. doi:10.1111/ iep. 12027

12. Franchi M, Trirè A, Quaranta M, Orsini E, Ottani V. Collagen structure of tendon relates to function. ScientificWorldJournal (2007) 7:404-20. doi:10.1100/ tsw.2007.92

13. Zhang G, Young BB, Ezura Y, Favata M, Soslowsky LJ, Chakravarti S, et al. Development of tendon structure and function: regulation of collagen fibrillogenesis. J Musculoskelet Neuronal Interact (2005) 5:5-21.

14. Kannus P. Structure of the tendon connective tissue. Scand J Med Sci Sports (2000) 10:312-20. doi:10.1034/j.1600-0838.2000.010006312.x

15. Benjamin M, Ralphs JR. Fibrocartilage in tendons and ligaments - an adaptation to compressive load. J Anat (1998) 193(Pt 4):481-94. doi:10.1046/j. 1469-7580.1998.19340481.x

16. Benjamin M, McGonagle D. Entheses: tendon and ligament attachment sites. Scand J Med Sci Sports (2009) 19:520-7. doi:10.1111/j.1600-0838. 2009.00906.x

\section{AUTHOR CONTRIBUTIONS}

$\mathrm{AP}$ and CS designed the study. AP, CS and BK collected the specimens. AP and BK conducted the molecular biological analysis. $\mathrm{AP}, \mathrm{KF}$ and $\mathrm{BK}$ performed the statistical analysis. AP assembled the results. AP prepared and edited the manuscript. CS and BK edited the manuscript. All authors read and approved the final version of the manuscript.

\section{ACKNOWLEDGMENTS}

We wish to thank Professor Dr. K. Fey (Clinic for horses-internal Medicine, Giessen) and Professor Dr. A. Wehrend (Clinic of Maternity, Gynecology, and Andrology, Giessen) for providing specimens.

17. Connizzo BK, Yannascoli SM, Soslowsky LJ. Structure-function relationships of postnatal tendon development: a parallel to healing. Matrix Biol (2013) 32:106-16. doi:10.1016/j.matbio.2013.01.007

18. Stoll C, John T, Endres M, Rosen C, Kaps C, Kohl B, et al. Extracellular matrix expression of human tenocytes in three-dimensional air-liquid and PLGA cultures compared with tendon tissue: implications for tendon tissue engineering. J Orthop Res (2010) 28:1170-7. doi:10.1002/jor.21109

19. Yang G, Rothrauff BB, Tuan RS. Tendon and ligament regeneration and repair: clinical relevance and developmental paradigm. Birth Defects Res C Embryo Today (2013) 99:203-22. doi:10.1002/bdrc.21041

20. Chen X, Yin Z, Chen J, Shen W, Liu H, Tang Q, et al. Force and scleraxis synergistically promote the commitment of human ES cells derived MSCs to tenocytes. Sci Rep (2012) 2:977. doi:10.1038/srep00977

21. Brent AE, Schweitzer R, Tabin CJ. A somitic compartment of tendon progenitors. Cell (2003) 113:235-48. doi:10.1016/S0092-8674(03)00268-X

22. Schweitzer R, Chyung JH, Murtaugh LC, Brent AE, Rosen V, Olson EN, et al. Analysis of the tendon cell fate using scleraxis, a specific marker for tendons and ligaments. Development (2001) 128:3855-66.

23. Cserjesi P, Brown D, Ligon KL, Lyons GE, Copeland NG, Gilbert DJ, et al. Scleraxis: a basic helix-loop-helix protein that prefigures skeletal formation during mouse embryogenesis. Development (1995) 121:1099-110.

24. Murchison ND, Price BA, Conner DA, Keene DR, Olson EN, Tabin CJ, et al. Regulation of tendon differentiation by scleraxis distinguishes force-transmitting tendons from muscle-anchoring tendons. Development (2007) 134:2697-708. doi:10.1242/dev.001933

25. Benjamin M, Qin S, Ralphs JR. Fibrocartilage associated with human tendons and their pulleys. J Anat (1995) 187(Pt 3):625-33.

26. DiCesare P, Hauser N, Lehman D, Pasumarti S, Paulsson M. Cartilage oligomeric matrix protein (COMP) is an abundant component of tendon. FEBS Lett (1994) 354:237-40. doi:10.1016/0014-5793(94)01134-6

27. Floyd A, Mansmann RA. Equine Podiatry. London: Elsevier Health Sciences (2007). $477 \mathrm{p}$

28. Marinovich R, Soenjaya Y, Wallace GQ, Zuskov A, Dunkman A, Foster BL, et al. The role of bone sialoprotein in the tendon-bone insertion. Matrix Biol (2016) 5(2-54):325-38. doi:10.1016/j.matbio.2016.01.016

29. Sharma P, Maffulli N. Biology of tendon injury: healing, modeling and remodeling. J Musculoskelet Neuronal Interact (2006) 6:181-90.

30. Ippolito E, Natali PG, Postacchini F, Accinni L, de Martino C. Morphological, immunochemical, and biochemical study of rabbit Achilles tendon at various ages. J Bone Joint Surg Am (1980) 62:583-98. doi:10.2106/00004623198062040-00014

31. Heinemeier KM, Schjerling P, Heinemeier J, Magnusson SP, Kjaer M. Lack of tissue renewal in human adult Achilles tendon is revealed by nuclear bomb (14)C. FASEB J (2013) 27:2074-9. doi:10.1096/fj.12-225599

32. Fenwick SA, Hazleman BL, Riley GP. The vasculature and its role in the damaged and healing tendon. Arthritis Res (2002) 4:252-60. doi:10.1186/ $\operatorname{ar} 416$ 
33. Müller SA, Todorov A, Heisterbach PE, Martin I, Majewski M. Tendon healing: an overview of physiology, biology, and pathology of tendon healing and systematic review of state of the art in tendon bioengineering. Knee Surg Sports Traumatol Arthrosc (2015) 23:2097-105. doi:10.1007/ s00167-013-2680-z

34. Magnusson SP, Heinemeier KM, Kjaer M. Collagen homeostasis and metabolism. Adv Exp Med Biol (2016) 920:11-25. doi:10.1007/978-3-31933943-6_2

35. Beertsen W, Everts V. The site of remodeling of collagen in the periodontal ligament of the mouse incisor. Anat Rec (1977) 189:479-97. doi:10.1002/ ar. 1091890308

36. Lekic P, McCulloch CA. Periodontal ligament cell population: the central role of fibroblasts in creating a unique tissue. Anat Rec (1996) 245:327-41. doi:10.1002/(SICI)1097-0185(199606)245:2<327::AID-AR15>3.0.CO;2-R

37. Warhonowicz M, Staszyk C, Rohn K, Gasse H. The equine periodontium as a continuously remodeling system: morphometrical analysis of cell proliferation. Arch Oral Biol (2006) 51:1141-9. doi:10.1016/j.archoralbio. 2006.05.013

38. Warhonowicz M, Staszyk C, Gasse H. Immunohistochemical detection of matrix metalloproteinase-1 in the periodontal ligament of equine cheek teeth. Tissue Cell (2007) 39:369-76. doi:10.1016/j.tice.2007.07.005

39. Perera KA, Tonge CH. Fibroblast cell proliferation in the mouse molar periodontal ligament. J Anat (1981) 133:77-90.

40. Nanci A. Ten Cate's Oral Histology: Development, Structure and Function. St. Louis: Elsevier (2013).

41. Henneman S, Von den Hoff JW, Maltha JC. Mechanobiology of tooth movement. Eur J Orthod (2008) 30:299-306. doi:10.1093/ejo/cjn020

42. Chen X, Li N, Yang L, Liu J, Chen J, Liu H. Expression of collagen I, collagen III and MMP-1 on the tension side of distracted tooth using periodontal ligament distraction osteogenesis in beagle dogs. Arch Oral Biol (2014) 59:1217-25. doi:10.1016/j.archoralbio.2014.07.011

43. Dixon WJ. BMDP Statistical Software Manual: To Accompany the 7.0 Software Release. Berkeley: University of California Press (1992).

44. FRISBIE DD, Smith RK. Clinical update on the use of mesenchymal stem cells in equine orthopaedics. Equine Vet J (2010) 42:86-9. doi:10.2746/0425 16409X477263

45. Burk J, Badylak SF, Kelly J, Brehm W. Equine cellular therapy - from stall to bench to bedside? Cytometry A (2013) 83:103-13. doi:10.1002/cyto.a.22216

46. Raabe O, Shell K, Goessl A, Crispens C, Delhasse Y, Eva A, et al. Effect of extracorporeal shock wave on proliferation and differentiation of equine adipose tissue-derived mesenchymal stem cells in vitro. Am J Stem Cells (2013) 2:62-73.

47. Raabe O, Shell K, Fietz D, Freitag C, Ohrndorf A, Christ HJ, et al. Tenogenic differentiation of equine adipose-tissue-derived stem cells under the influence of tensile strain, growth differentiation factors and various oxygen tensions. Cell Tissue Res (2013) 352:509-21. doi:10.1007/s00441-013-1574-1

48. Sakaguchi Y, Sekiya I, Yagishita K, Muneta T. Comparison of human stem cells derived from various mesenchymal tissues: superiority of synovium as a cell source. Arthritis Rheum (2005) 52:2521-9. doi:10.1002/art.21212

49. Burk J, Gittel C, Heller S, Pfeiffer B, Paebst F, Ahrberg AB, et al. Gene expression of tendon markers in mesenchymal stromal cells derived from different sources. BMC Res Notes (2014) 7:826. doi:10.1186/1756-0500-7-826

50. Martinello T, Bronzini I, Perazzi A, Testoni S, De Benedictis GM, Negro A, et al. Effects of in vivo applications of peripheral blood-derived mesenchymal stromal cells (PB-MSCs) and platlet-rich plasma (PRP) on experimentally injured deep digital flexor tendons of sheep. J Orthop Res (2013) 31:306-14. doi:10.1002/jor.22205

51. Watts AE, Yeager AE, Kopyov OV, Nixon AJ. Fetal derived embryonic-like stem cells improve healing in a large animal flexor tendonitis model. Stem Cell Res Ther (2011) 2:4. doi:10.1186/scrt45

52. Schnabel LV, Lynch ME, van der Meulen MC, Marjolein $\mathrm{CH}$, Yeager AE, Kornatowski MA, et al. Mesenchymal stem cells and insulin-like growth factor-I gene-enhanced mesenchymal stem cells improve structural aspects of healing in equine flexor digitorum superficialis tendons. J Orthop Res (2009) 27:1392-8. doi:10.1002/jor.20887

53. Violini S, Ramelli P, Pisani LF, Gorni C, Mariani P. Horse bone marrow mesenchymal stem cells express embryo stem cell markers and show the ability for tenogenic differentiation by in vitro exposure to BMP-12. BMC Cell Biol (2009) 10:29. doi:10.1186/1471-2121-10-29
54. Yin Z, Guo J, Wu T, Chen X, Xu L, Lin S, et al. Stepwise differentiation of mesenchymal stem cells augments tendon-like tissue formation and defect repair in vivo. Stem Cells Transl Med (2016) 5:1106-16. doi:10.5966/ sctm.2015-0215

55. Vandenberghe A, Broeckx SY, Beerts C, Seys B, Zimmerman M, Verweire I, et al. Tenogenically induced allogeneic mesenchymal stem cells for the treatment of proximal suspensory ligament desmitis in a horse. Front Vet Sci (2015) 2:49. doi: $10.3389 /$ fvets.2015.00049

56. Hsieh C, Alberton P, Loffredo-Verde E, Volkmer E, Pietschmann M, Müller PE, et al. Periodontal ligament cells as alternative source for cell-based therapy of tendon injuries: in vivo study of full-size Achilles tendon defect in a rat model. Eur Cells Mater (2016) 32:228-40. doi:10.22203/eCM.v032a15

57. Freezer SR, Sims MR. A transmission electron-microscope stereological study of the blood vessels, oxytalan fibres and nerves of mouse-molar periodontal ligament. Arch Oral Biol (1987) 32:407-12. doi:10.1016/0003-9969 (87)90075-6

58. McCulloch CA. Origins and functions of cells essential for periodontal repair: the role of fibroblasts in tissue homeostasis. Oral Dis (1995) 1:271-8. doi:10.1 111/j.1601-0825.1995.tb00193.x

59. Svensson RB, Heinemeier KM, Couppé C, Kjaer M, Magnusson SP. Effect of aging and exercise on the tendon. J Appl Physiol (2016) 121:1353-62. doi:10.1152/japplphysiol.00328.2016

60. Thorpe CT, Streeter I, Pinchbeck GL, Goodship AE, Clegg PD, Birch HL. Aspartic acid racemization and collagen degradation markers reveal an accumulation of damage in tendon collagen that is enhanced with aging. J Biol Chem (2010) 285:15674-81. doi:10.1074/jbc.M109.077503

61. Kalson NS, Lu Y, Taylor SH, Starborg T, Holmes DF, Kadler KE. A structure-based extracellular matrix expansion mechanism of fibrous tissue growth. Elife (2015) 4:1-22. doi:10.7554/eLife.05958

62. Birk DE, Mayne R. Localization of collagen types I, III and V during tendon development. Changes in collagen types I and III are correlated with changes in fibril diameter. Eur J Cell Biol (1997) 72:352-61.

63. Liu X, Wu H, Byrne M, Krane S, Jaenisch R. Type III collagen is crucial for collagen I fibrillogenesis and for normal cardiovascular development. Proc Natl Acad Sci U S A (1997) 94:1852-6. doi:10.1073/pnas.94.5.1852

64. Tozer S, Duprez D. Tendon and ligament: development, repair and disease. Birth Defects Res C Embryo Today (2005) 75:226-36. doi:10.1002/bdrc.20049

65. Butler WT, Birkedal-Hansen H, Beegle WF, Taylor RE, Chung E. Proteins of the periodontium. Identification of collagens with the [alpha1(I)]2alpha2 and [alpha1(III)] 3 structures in bovine periodontal ligament. J Biol Chem (1975) 250:8907-12.

66. Pandav G, Saxena D, Kaur H, Jain S, Dewan A. Collagen: basis of life. Univ Res J Dentistry (2014) 4:1. doi:10.4103/2249-9725.127046

67. Shuttleworth CA, Forrest L. Changes in guinea-pig dermal collagen during development. Eur J Biochem (1975) 55:391-5. doi:10.1111/j.1432-1033.1975. tb02174.x

68. Epstein EH. (Alpha1(3))3 human skin collagen. Release by pepsin digestion and preponderance in fetal life. J Biol Chem (1974) 249:3225-31.

69. Takimoto A, Kawatsu M, Yoshimoto Y, Kawamoto T, Seiryu M, TakanoYamamoto $\mathrm{T}$, et al. Scleraxis and osterix antagonistically regulate tensile force-responsive remodeling of the periodontal ligament and alveolar bone. Development (2015) 142:787-96. doi:10.1242/dev.116228

70. Léjard V, Brideau G, Blais F, Salingcarnboriboon R, Wagner G, Roehrl MH, et al. Scleraxis and NFATc regulate the expression of the pro-alphal(I) collagen gene in tendon fibroblasts. J Biol Chem (2007) 282:17665-75. doi:10.1074/jbc. M610113200

71. Maeda T, Sakabe T, Sunaga A, Sakai K, Rivera AL, Keene DR, et al. Conversion of mechanical force into TGF- $\beta$-mediated biochemical signals. Current Biol (2011) 21:933-41. doi:10.1016/j.cub.2011.04.007

72. Mori N, Majima T, Iwasaki N, Kon S, Miyakawa K, Kimura C, et al. The role of osteopontin in tendon tissue remodeling after denervation-induced mechanical stress deprivation. Matrix Biol (2007) 26:42-53. doi:10.1016/j. matbio.2006.09.002

73. Cordes V, Lüpke M, Gardemin M, Seifert H, Staszyk C. Periodontal biomechanics: finite element simulations of closing stroke and power stroke in equine cheek teeth. BMC Vet Res (2012) 8:60. doi:10.1186/1746-6148-8-60

74. Schrock P, Lüpke M, Seifert H, Borchers L, Staszyk C. Finite element analysis of equine incisor teeth. Part 1: determination of the material parameters of the periodontal ligament. Vet J (2013) 198:583-9. doi:10.1016/j.tvjl.2013.10.009 
75. Xiong J, Gronthos S, Bartold PM. Role of the epithelial cell rests of Malassez in the development, maintenance and regeneration of periodontal ligament tissues. Periodontol 2000 (2013) 63:217-33. doi:10.1111/prd.12023

Conflict of Interest Statement: None of the authors of this paper has a financial or personal relationship with other people or organizations that could inappropriately influence or bias the content of the paper.
Copyright (c) 2018 Pöschke, Krähling, Failing and Staszyk. This is an open-access article distributed under the terms of the Creative Commons Attribution License (CC BY). The use, distribution or reproduction in other forums is permitted, provided the original author(s) or licensor are credited and that the original publication in this journal is cited, in accordance with accepted academic practice. No use, distribution or reproduction is permitted which does not comply with these terms. 